\title{
X-Linked Dominant Inheritance
}

National Cancer Institute ( $\mathrm{NCl})$

\section{Source}

National Cancer Institute (NCI). X-linked dominant inheritance.

X-linked dominant inheritance refers to genetic conditions associated with mutations in genes on the $\mathrm{X}$ chromosome. A single copy of the mutation is enough to cause the disease in both males (who have one $X$ chromosome) and females (who have two $X$ chromosomes). In some conditions, the absence of a functional gene results in the death of affected males. 